\title{
Mediated learning and foreign language acquisition
}

\author{
David N. Brown
}

\section{(2) OpenEdition}

\section{Journals}

Édition électronique

URL : http://journals.openedition.org/asp/1651

DOI : 10.4000/asp. 1651

ISBN : 978-2-8218-0388-6

ISSN : 2108-6354

Éditeur

Groupe d'étude et de recherche en anglais de spécialité

Édition imprimée

Date de publication : 1 décembre 2002

Pagination : 167-182

ISSN : 1246-8185

Référence électronique

David N. Brown, « Mediated learning and foreign language acquisition », ASp [En ligne], 35-36 | 2002, mis en ligne le 27 août 2010, consulté le 30 avril 2019. URL : http://journals.openedition.org/asp/1651 ; DOI : 10.4000/asp.1651

Ce document a été généré automatiquement le 30 avril 2019

Tous droits réservés 


\title{
Mediated learning and foreign language acquisition
}

\author{
David N. Brown
}

\section{Introduction}

1 Specialists in the area of motivation, Wlodkowski (1993) to name but one, argue convincingly that it is the root of success in any learning situation. It is the root of success particularly in learning contexts such as ours where students who are specialists in other, frequently scientific areas, are not always as co-operative as one may hope. Doubtless, if many of our students find learning a foreign language just a little taxing to say the least, if they give the impression that minimum effort is the only approach, if it seems that they would rather be elsewhere, then there must be a reason. The reason is that they are not interested in the process, all they want is the finished product. They do not want to learn English, they would like to have learned English. Whatever the input energy might be, the resulting behaviour is one that denotes demotivation and whatever their duties to themselves or their responsibilities to the institute might be, demotivation is unavoidably a problem that concerns teachers.

2 Mainstream motivational psychology, even though it recognises the existence of extrinsic factors, invariably puts the onus on the actor. Extrinsic motivation, as it is called, is not considered genuine. Indeed, it implies that the actor becomes a mere object in his own play. Such situations invariably raise questions for if it is certainly true that responsibility must rest on the shoulders of the individual - and this, in many respects, is what learnerdirected learning is all about - it is also beyond doubt that behaviour results from environmental considerations, while perceived environments are in fact the reconstructed image of reality which has passed through the filter of perception. In short, a negotiation takes place between the actor and reality that results in a construct which to all intents and purposes can be considered virtual.

3 Mediation theory, a cousin of the motivational psychology family, seems to have been overlooked by mainstream motivational psychologists. None of the literature in the field 
of education, for example, brings mediated learning experience (MLE), into the equation. The reason is simple: whereas mainstream motivational psychology is to do with the behaviour of the individual within and as a direct result of the environment, MLE approaches the question from the point of view of the buffer between the individual and the environment, placing the onus on the intermediary. Hence, seen in this light, the teacher is more than a bearer of knowledge, a traditional role which, even from the point of view of autonomous learning, is not jeopardised, but also the refining element that imparts the appropriate coloration on perception at the right time to promote attainment of the learning goal. As a result, responsibility for learning is lightened while responsibility for making learning a possibility is increased. The former is the domain of the learner, the latter that of the teacher who assumes the role of mediator.

\section{Mediation theory as applied to language learning}

4 Within the context of foreign language learning MLE could be briefly defined as the interaction of a learner with the learning environment via the language instructor who assumes the role of human mediator. The danger with such a sweeping definition is the tendency to consider all learner / environment interactions as bearing the characteristics of MLE. Why should the act of spontaneously correcting a learner on the verge of making a grammatical error not be considered as MLE? In fact, is there any reason not to consider all teaching approaches as MLEs? After all, even the use of language laboratories, computers or video, all of which form a bridge between the learner and the foreign language, constitute a mediation of sorts. Such over-extension has already happened in areas of learning where attempts to apply MLE are current. When mistakes occur, they seem to stem from the fact that MLE requires on the part of the mediator a process of volition, choice and the capacity to adapt to the mediatee. If this basic requirement is fulfilled, there is good reason to believe that MLE can be applied successfully to all areas.

If MLE is appropriate to all areas of learning, it is perhaps not appropriate for all learners.

Many may experience greater or lesser difficulty transferring data they were previously exposed to in controlled learning situations to new contexts which, incidentally, may be just as controlled. For example, why would more than half a group of 27 remedial students (that is to say, students who were far from reaching the institutionally required level of English) fail to apply a simple, previously-taught language concept when given the opportunity to do so during a follow-up activity? How is it that they depended so heavily on guess-work and the process of elimination?

It is language learners such as these who would benefit most from MLE. These students are intelligent (at least in the academic sense), they are not handicapped by learning difficulties or difficulties in understanding complex concepts nor do they have memory problems. The lacuna from which they suffer is on a cultural level. Simple observation reveals how some categories of student seem to have very little difficulty carrying out and even enjoying language-learning tasks, while others (in the case above, engineering students) do not. The explanation surely lies in cultural differences that engender detrimental attitudes and subject prejudices.

7 The difference between the two categories of student is to do with Feuerstein's theory of Structural Cognitive Modifiability. His theory states that the capacity of a learner to become "modified" as a result of exposure to a stimulus depends not on intelligence, nor on other factors which grass roots teachers usually associate with learning capacity, but 
on culture. In other words, those who display positive behaviour towards chosen areas, whether these be social requirements or academic subjects, will tend to perform better in those areas.

8 Those who do not possess such predispositions, in our case towards the particular area labelled "learning a foreign language", will display an incapacity to become modified. As a result, they will have difficulty in benefiting from the experience to which they are exposed no matter how many times the experience is renewed. In order for them to benefit from exposure to the foreign language, these learners need an approach from the teacher that takes him beyond his usual outlay because, unlike other individuals, his learners are not fitted out psychologically to benefit from either formal (for example, grammar and vocabulary exercises) or informal (for example, fluency exercises) opportunities to improve language proficiency. To put it in a nutshell, this deprived category of learners have to "learn to learn" via the mediation of the language teacher in order to achieve the same result that others achieve via traditional direct exposure to the stimuli. The ideal candidate for MLE is a

culturally deprived individual [...] who, either not having been exposed or not having been able to benefit from his exposure to mediated learning experience, is devoid of learning tools, habits, dispositions, and propensities to learn. His 'modifiability', (i.e. his capacity to benefit from formal and informal learning) is more or less restricted. (Feuerstein \& Rand 1975: 17)

He will frequently come across as being rigid, unable to adapt and lacking energy.

In view of its aims, MLE could be labelled as the vehicle of interaction between the learner and the learning environment. It is not exclusive in that it must take place in parallel to continued direct exposure to the stimuli. It has a role to play because the typical candidate for MLE lacks the capacity to digest the flow of stimuli, which can vary both in frequency and intensity leaving him overwhelmed and at a loss.

\section{The parameters of MLE}

10 MLE is of value in a learning situation because it enhances quality. It supplements but is not intended to replace direct stimuli which, because of their non-mediated nature, can complicate the process of learning. MLE in action, as applied to the language learning context, is recognised by the following characteristics.

\section{Intentionality and reciprocity}

These are the main conditions of MLE. With intentionality, a particular learnerperception of the stimulus (e.g., a listening task with comprehension questions, a grammar exercise, a speaking activity) is promoted by the teacher through his introduction of the stimulus. The comparison of two typical sets of instructions illustrates this. The first is as follows: "Listen to the news excerpt on the tape and find the answers to the questions." Why should the learners listen? Observations carried out by Chambers (1996: 24) suggest that it is unlikely that there is any intrinsic motivation to listen. The learners are just doing what the teacher tells them to do. On the other hand, "The news excerpt on the tape is in a US accent. As you can imagine, being accustomed to the US accent is essential if you want to pass your TOEFL which you must have if you intend to spend a year at Florida Tech. The questions on the work sheet are merely to focus your 
attention on certain words and turns of phrase rather than information. You are probably familiar with the information content as it concerns current affairs and in particular international terrorism." Granted, this is somewhat longer than the previous rather terse set of instructions. But it does transform an implicit intention on the part of the teacher into an explicit and clearly thought through process. Also, such lengthy instructions could be said to spill over into the notion of transcendence, the second MLE parameter. The reciprocity is in the relational aspect set up between the teacher and the group of learners. "I've prepared this for you because of your ambition to study abroad. You do the exercise for me so that I can enable you to reach your goal." However, intentionality and reciprocity are efficient tools only when the language learning context is genuinely meaningful. In other words, their effect may be considerably blunted when the only motive for attending a language course is because it is on the syllabus.

\section{Transcendence}

This involves going beyond the immediate intended goals of the stimulus. A sufficiently long series of US news excerpts will eventually accustom the learner to the US accent to the point that listening difficulties encountered at Florida Tech, or elsewhere, will not be directly attributable to the accent itself. This simple objective can be transcended in two ways. First, the learner has no way of being sure that he has effectively acquired this skill. But nurturing his feeling of competence within that skill goes beyond the skillsacquisition activity and contributes as much to better performance as being proficient does. Second, on perhaps a lower level, using video in the activity described previously would transcend the objective of accent acclimatisation. The video, in addition to its value in the area of so-called optemics, can be seen to serve as a motivational stimulus (Brown 2000) for those in pursuit of language acquisition. It also exploits a culturally well-embedded need system that links TV to feelings of pleasure, enjoyment, relaxation and leisure. Consequently, transcendence can be said to broaden the immediate goal to include more remote goals.

\section{Mediation of meaning (MoM)}

The reason why we do things is not always obvious. Nor, on the whole, do we usually make any attempt to justify ourselves. As Feuerstein et al. put it,

The pedagogical and didactical reasonings of teachers are often kept secret from the student to the point that one considers this 'secrecy' a main characteristic of pedagogic theory and practice. (1980: 67)

MoM makes the significance of a stimulus clear. This, in some respects, may run against the grain of mainstream views in language learning pedagogy. The belief that the development of an individual's learning styles as a set of uniquely personalised skills would tend to dilute anything positive to be gained from MoM. Although it may be a laudable desire to see the learner make his own choices and discover the methodology that will best suit his needs, the result may be that the effect of the stimulus is reduced. Without explanation, the learner is working in the dark until such a time that, having engineered his own approach, he arrives at the end of the tunnel - if, indeed, he ever does. Furthermore, the fact that many teachers do not feel the need to explain themselves may simply be a symptom of the lack of any form of affective relationship between them and their learners. It also implies that the learners are not being treated as 
normal human beings. Preparing a learner to carry out a task he may not be interested in doing is as important as preparing the task itself. Everybody knows the saying about the horse, the trough and the drinking of water. In other words, MoM may be the key to making the teacher's efforts in task preparation pay off. Also, MoM can have a knock-on effect in that the learner who is used to having the whys and wherefores of a task explained to him should eventually develop both the need and the capacity to find the answers himself. In other words, the goals of what are referred to above as the mainstream views in language learning pedagogy are, nevertheless, fulfilled in a roundabout way.

\section{Mediation of feeling competent}

15 Just as some extremely competent people feel thoroughly incompetent, others who may possess comparatively little knowledge in a particular foreign language may feel extremely capable. This, of course, is the well-known dichotomy of knowledge versus ability and is very much to do with self-worth theory and achievement motivation.

Indeed, when students equate their worth with the ability to achieve, the maintenance of feelings of competency becomes of paramount importance even when self-protective strategies may cause the very failures that individuals are trying to avoid. (Covington and Roberts 1994: 161)

16 People who feel competent may perform better than those who do not, irrespective of their real level of knowledge. Helping students to become aware of what they can do in spite of their failings is a sine qua non of their assuming total responsibility for their learning. This may be particularly true in contexts where "high-performance" students (in French culture this refers especially to engineering students with a maths and physics background) with set beliefs about their future (and, therefore, what they should be doing to attain that future) are confronted with unexpected realities. The vastness of the task and inherent skills in foreign language learning is beyond them. "Language lessons reveal to them perhaps more than other lessons the extent of their inadequacy" (Chambers 1993: 13). Possibly, therefore, to an even greater extent than for other categories of student, tasks in FL teaching need to be designed in order to allow positive feedback. Traditional grading, assessing and evaluating could be set temporarily to one side. Killing the learners with kindness, however, is a danger that easily seeps in - it seems uncontroversial that setting inappropriately low tasks would do as much to undermine expectations as would making them too difficult.

\section{Mediation of regulation and control of behaviour}

17 This is said to be quantitatively one of the most important dimensions of interaction between teachers and learners as it involves either initiating or preventing types of behaviour. Drawing attention to specific points, accentuating, accelerating or decelerating progression through activities, explaining causal relationships and giving instructions are among the most frequent aspects to be encountered in language teaching. The theory is that behaviour regulated and controlled in this way cultivates the adaptability required for a reticent learner to become modified. But control, or more precisely controlling the learner, is a dangerous thing to do. In effect, control, along with choice, challenge and collaboration, is one of the four pillars of what is referred to as "situated motivation" (cf. Paris \& Turner 1994: 213). Ryan and Grolnick (1986: 556) found 
that when control is displaced towards the learner the pay-off is that he will gain in interest, perceived confidence and self-worth. If the teacher holds on too closely, the opposite result may be brought about. The teacher is tacking through a dangerous strait here, because relinquishing too much control too early can result in a failure to cultivate adaptability.

\section{Mediation of sharing behaviour}

This is the individual's need to belong by participating with others and by encouraging others to participate with him. In this way, individuals give reality to their experiences (e.g., reporting on a near-fatal motor accident or on a conflict with a student during a lesson). It is also a means of sharing one's inner life with others (relating dreams, worries and the like). On the day-to-day level, it is frequently manifested through bonding activities like, for example, when teachers stand in the hall smoking with their students during the break, when they go for a drink together on a Friday after class or even when they have a meal together. The affective links set up by such behaviour are seen to have positive effects in the more formal pedagogical context.

\section{Mediation of individual and psychological differentiation}

This may seem to contradict the previous parameter. Individuation is the opposite of sharing. It is the need to assert oneself as a separate individual who, nevertheless, shares certain aspects of his existence with the community. Individual and psychological differentiation is the process by which the individual becomes separate. Paradoxically, it is in environments where sharing behaviour is at its strongest that individual and psychological differentiation takes place most smoothly. So, the learner who is capable of genuine autonomy is the one who, through the process of mediation, has been prepared for the situation in an environment close to a more traditional mode of teaching / learning.

\section{Mediation of goal-seeking, goal-setting and goal-achieving behaviour}

20 Goal seeking is a means of enriching the learning process. It requires organisational skills to be brought into play and creates the necessity to develop the tools to achieve the goal. In the absence of genuine learning goals, motivation can be no more than instrumental and, therefore, lacking in efficacy. This, of course, does not mean to say that learning does not take place. Gardner and MacIntyre (1991: 62) have shown that immediate gratification in the form of monetary rewards boosts study time in the learning of French vocabulary. They also revealed that removal of the financial incentive resulted in less effort. What this implies is that the short-term goal of earning money carried more weight than the remote goal of language proficiency. From that, it is reasonable to presume that the benefit of the initial effort was later lost when, their effort having diminished, the learners forgot what they had initially learned. The learning goal in this instance was not genuine. 


\section{Mediation of challenge}

21 One could summarise intelligence as being the capacity to deal with the unexpected sufficiently quickly. Preparing learners to take up that sort of challenge should be the goal of all education. Functioning in a foreign language continually presents the individual with all sorts of new and unexpected situations. Learning to confront these in the language classroom implies on the one hand assigning tasks that can be solved after reasonable effort. In other words, such tasks gratify the learner who takes up the challenge. At the same time, the teacher must avoid "mothering" the learners as he so often does without realising it. The pause-button story is enough to illustrate this. Chambers (1996: 24) relates how the index fingers of some teachers constantly hover over the pause button on cassette players. As soon as the learners frown or look puzzled, down goes the finger. What Chambers refers to as "this stop-start approach" deprives the learners of the chance to piece the story together for themselves, to develop the skill of inference and to hypothesise as to the meaning and pronunciation of words unknown or difficult to make out. Abuse of the pause button in this way is the best means of nurturing panic reactions when learners have to face the real thing. Other examples abound: explaining all of the vocabulary in a reading and correcting every error during oral expression to mention but two.

\section{Mediation of the awareness of the human being as a changing entity}

Once a person is labelled, particularly if that label happens to be a negative one, it is extremely difficult to change other people's opinions. Examples are useless here. It is sufficient to look around one's immediate circle for easily-substantiated anecdotal evidence of this. The human need for stability is in large part responsible for such attitudes. Hence, even individuals capable of change tend to be quickly written off. It may be true that an individual's educational development is predictable but only within the limits of the institute's approach to teaching and what it recognises as a valid route to a specific goal. Non-achievement of a goal is frequently interpreted as a lack of intelligence. So learners who cannot, or who refuse to conform to the institute's view of problemsolving are labelled as irretrievable and, consequently, excluded either physically or psychologically. The number of times unfair judgement has been passed on recalcitrant learners of English illustrates this. In other words, teacher attitudes can be summarised as: we know them well enough to be able to rule that they cannot achieve the objective. The idea that the learners may be modifiable, or may have even gone through a process of modification on a level sufficient to achieve the goal set by the institute rarely occurs to teachers.

\section{Mediation of the search for an optimistic alternative}

The above description could be reformulated as follows: why search for a solution that does not exist. Mediation of the search for an optimistic alternative is in direct opposition to this attitude. Passive acceptance of an undesirable situation is not only less courageous but it is also said to inhibit the necessary cognitive activity that leads to problem solving. Most language teachers have come up against the "can't-learn-won't learn" attitude. This 
pessimistic attitude in itself is sufficient to trigger the passive approach that undermines any possibility of commitment to a solution. Learners who succeed do so because by nature they anticipate a positive outcome and, as a result, bring into play the personal cognitive strategies that are conducive to finding solutions.

\section{Mediation of the feeling of belonging}

The final one is perhaps the most difficult of Feuerstein's parameters to adapt to the area of language learning. On a broader level, the feeling of belonging is linked to society, the extended family, the problems incurred by the isolated nuclear family and, ultimately, alienation. A number of questions arise: how is alienation to learning a foreign language related to the concept of belonging? Is such alienation inherent only to the learning of English rather than any other language? Is the alienation typical of French culture? There are good historic reasons for French antipathy towards the English. By extension, there are good reasons for a feeling of exasperation, and the concomitant linguistic protectionism generated thereby, when the language of an ex-colonial empire ends up playing second fiddle to the language of another ex-colonial empire that has become the international lingua franca for reasons that have nothing to do with the virtues of Englishness, however theoretical they may be. The fact remains that a learner who is isolated from the rest of the learning group within the institute, for whatever reason, has the odds stacked against him. Problems caused by the lack of integration of foreign students in French universities are enough to illustrate this. When this lack of integration is brought to the fore, it is frequently at a time when the semester's grades are being exposed under the harsh scrutiny of faculty juries.

The above parameters of mediated learning experience closely parallel Feuerstein's mediated learning theory (1980: 15-49). Of the twelve, only the first three are absolutely necessary. The others depend on the culture of the individual, on modes of learning and on cognitive styles. Feuerstein's views, in contrast to traditional Piagetian ones, stipulate that learning / development can be more or less successful according to the behaviour and attitudes of, as well as the approach adopted by, the learner's mediators. Mediators include any significant adult, especially the teachers at a later stage of learner's development. MLE applied to language learning could have interesting results, just as the absence of MLE probably leads to significant undesirable results.

\section{The MLE questionnaire}

Past attempts to observe the frequency or nature of mediation that takes place in the language-learning classroom are few and far between. One mediation questionnaire designed by Warren (1995) allows language teachers to evaluate the mediation that takes place in their own classroom. This requires the presence of an observer who subsequently negotiates completion of the questionnaire with the teacher. Warren's method does not produce statistical results as such. It is completed with the help of the observer and allows individuals to concentrate on areas where their mediating style is inadequate or non-existent. The observer's role is to draw attention to mediation flaws which the teacher may have missed. It requires the will on the part of the teacher to apply mediation to the full and a readiness to accept comments and suggestion from an outsider. 
Another two-part questionnaire was designed by Chin (1990) in Mandarin Chinese and completed by 50 teachers in Taiwan (more on his statistics later). Chin's questionnaire was adapted by the present writer who produced a version in French. Both parts can be seen in Appendix A. It is made up of two sets of 12 questions, each reflecting one parameter of mediation described above. It was sent out by e-mail to language teachers in university non-specialist language departments across France via a number of informal and professional networks, including GERAS. Teachers were asked to fill in the first part before moving on to the second part. Indeed, the focus of each section differs slightly. Part I solicits feedback on what teachers consider to be important, while Part II solicits feedback on what they actually do. Addressees were also warned about the similitude between each part in spite of the contrasting focus. They were invited to return the questionnaire either by e-mail or by post if they wished to remain anonymous. Of the 487 copies sent out, 90 came back duly completed. Only 17 of these were returned by post and most of those were accompanied by a note of encouragement and signed by the senders. Clearly, then, in this particular instance, anonymity was considered of little importance. However, some recipients did express the difficulty they experienced filling in the questionnaire, this difficulty being linked to the teaching environment they worked in (for example, teachers who interacted only in lecturing mode in large lecture halls). Others expressed misgivings over the format of the questionnaire (for example, they felt that the evaluation should have been on a scale of 1 to 5 rather than 1 to 10), but the desire to parallel Chin's version with the intention to compare some of the results dictated format.

\section{The results}

The goals of the questionnaire were threefold and each could be the topic of a separate paper. Should the opportunity arise they will be. They were:

1. Ascertain as to what degree mediation of the type described in points 1 to 12 above takes place in French university non-specialist English language classrooms.

2. Isolate the parameters of mediation that are typical of French culture or, at least, typical of the French non-specialist English language-teaching context in French universities.

3. Compare results with those obtained by Chin.

This is an on-going study and too much detail at this stage would be both tedious and premature. Consequently, results related to the three points above are presented succinctly in the following three corresponding sections.

\section{Mediation in French university non-specialist English language classrooms}

30 Taking the statistics overall, there can be no question as to the existence of mediation in FL non-specialist classrooms in France. The majority of the sample (82\% attributing a score of 6 or more) reports on having actually engaged in what they perceive to be mediation-type interaction with their students to some degree or another. This is borne out by the fact that an average of $82 \%$ of responses to the questionnaire receive a score of 6 or more in Part II of the questionnaire - this part of the questionnaire is concerned with what the teacher actually does. Most readers would probably assume that such a result 
would be a foregone conclusion, but, given the particular structure of French university education that is still extremely Messianic especially in disciplines that involve training in the so-called "hard sciences", one must be careful of the discrepancy between what one could describe as wishful thinking and reality. Also, there may be a further discrepancy between what an individual teacher perceives as mediation and the amount of mediation that actually takes place (this highlights the usefulness of Warren's approach). Finally, the result brings forth another pressing question: of the $82 \%$, what proportion is ethnic French and what proportion is mother tongue (Anglo-Saxon, British, Irish and, to a certain extent, New Commonwealth)?

\section{The parameters of mediation that are typical of the non-specialist English language-teaching context in French universities}

31 The number of replies to the questionnaire, as stated above 90 , immediately begs the question as to whether the cross-section gives a true and accurate image of the real situation in English language teaching departments for non-specialists in French universities. However, 90 is almost double Chin's sample and represents a fairly good, although blurred reflection of the real situation.

The table in figure 1 summarises the figures.

Figure 1: Global Analysis of the Questionnaire

\begin{tabular}{|l|l|l|l|l|l|l|l|l|l|l|l|l|}
\hline Question & 1 & 2 & 3 & 4 & 5 & 6 & 7 & 8 & 9 & 10 & 11 & 12 \\
\hline $\begin{array}{l}\text { Ce qu'il est important } \\
\text { de faire }\end{array}$ & $100 \%$ & $83 \%$ & $80 \%$ & $100 \%$ & $97 \%$ & $73 \%$ & $80 \%$ & $90 \%$ & $80 \%$ & $87 \%$ & $83 \%$ & $83 \%$ \\
\hline $\begin{array}{l}\text { Ce que fait l'enseignant } \\
\text { réellement }\end{array}$ & $100 \%$ & $100 \%$ & $83 \%$ & $87 \%$ & $90 \%$ & $63 \%$ & $77 \%$ & $73 \%$ & $68 \%$ & $80 \%$ & $87 \%$ & $80 \%$ \\
\hline
\end{tabular}

Percentage of the sample having attributed a score of 6 out of 10 or more to each question in Part I and Part II

Question $\mathrm{N}^{\circ} 1$ is related to the parameter of intention and reciprocity (the first parameter of MLE). It is the only question where a unanimous group trend, both in what is considered important and in what is actually done, is present. However, the fact that all teachers in the sample consider this parameter important and are satisfied that they apply it, does not mean that it is applied according to the precepts adapted from Feuerstein's theory in the section on the parameters of MLE (see the example drawn from an exercise on news excerpts in that section). In any event, teachers seemingly and unsurprisingly perceive the idea of clear and well-understood intentions as a doorway to successful task fulfilment.

The next MLE parameter (mediation of meaning) dealt with in the questionnaire (Question 2) fares less well. Also, the sample's response is unexpected. There can be no doubt that life has a habit of coercing individuals into compromise. Thinking a certain behaviour important but not being able to apply it is a perfectly natural occurrence. The reverse, thinking an action unimportant and having to do it anyway may happen too. However, one expects such occurrences to be linked to life's trivia. $83 \%$ of the sample 
believes that mediation of meaning is important. In view of the implications of MoM, one would expect a higher percentage. But $100 \%$ of the sample engages in MoM-type interactions. Consequently, $17 \%$ seem to think MoM is unimportant, but they do it as a matter of course. Are these teachers being drawn into what they consider unnecessary as a result of negative reactions on the part of the learners? Do they prefer, on the other hand, learners to generate their own interpretations and discover they cannot? Alternatively, this might merely be a lack of coherence. Finally, it may be true that some teachers choose to do things they consider useless. Precise interpretations are not possible in this instance. The fact remains that learners must be able to identify with learning tasks for them to be successful. Teachers surely have a duty to promote this.

A similar proportion (80\%) of English teachers think that transcendence is important (Question 3 in the questionnaire). Using a video listening activity on industrial conflict to broach the question of employment legislation in Britain or the US and to compare either of these to the French equivalent could be extremely stimulating for the learner. Here, the language learning activity is transcended in two ways: by the video (previously mentioned) and, on the cultural level, by the legal comparison. Of the sample, 83\% (once again a paradoxically higher figure) of the teachers in the sample say they approach, on occasion at least, learning tasks similarly. Of course, statistics are misleading for only 18 (Appendix B2) of the sample actually do this with considerable regularity (reflected in the 10 out of 10 score).

So far, the discussion on statistics has examined only the parameters essential to MLE those covered by questions 1, 2 and 3. The statistics tend to indicate that mediated learning in the English language classroom is a going concern or is of some interest to the majority of English teachers in that the basic volitional conditions are fulfilled (parameters 1,2 and 3). This perhaps was to be expected: some might even say that it is what good language teaching is all about. But the figures do not tell us anything about the processes that may be used to apply ML, nor do they give us any means to compare the actions of teachers who attribute identical scores but who may perceive the same ML parameter and what it entails in radically different ways.

The remainder of this discussion will briefly examine some, but not all of the remaining responses - those that teachers seem to consider, from a statistical point of view, the more important ones, and those that raise further questions because the responses generate unexpected results. Overall, there do not seem to be any definite trends attributable to cultural, learning or cognitive characteristics. One could speculate, however, that the strong tendencies (defined as such in an arbitrary fashion because they score $90 \%$ or more) reflected in responses to questions 4,5 and 8 do indeed represent a cultural trend. These correspond to MLE parameters of competence, regulation and control of behaviour, and awareness of change respectively. The concept of building tasks so that students can exploit what they already know does have pride of place within the communicative approach. It has become the overarching orthodoxy in the English teaching world today. Such tasks almost certainly boost the learner's feeling of confidence. One of the difficulties faced by teachers of English to a non-specialist audience is the latter's tendency towards passiveness induced by uneasiness when it comes to speaking. It seems natural, therefore, that teachers should attempt, consciously or not, to dispel such feelings.

As we have seen, regulation and control of behaviour are very much teacher activities. It should come as no surprise, therefore, that almost the entire sample (97\%) consider it 
important. But what of mediation of an awareness of the human being as a changing entity (MLE parameter $\mathrm{N}^{\circ} 10$ and Question $\mathrm{N}^{\circ} 8$ )? Surprisingly, awareness of change appears extremely high on the sample's list of important items (90\%). Clearly, one must remain as open-minded as possible, accepting that individuals can and do evolve. But the definitive labelling of difficult learners is still a common occurrence across the language teaching community as a whole. Activities that may help the learner to become aware of his evolution do not, at least if this writer's observations are anything to judge by, receive tremendous amounts of classroom time either. Certainly, feedback such as test results, grades or even written evaluations is widespread, but these hardly contribute to nurturing in the learner a capacity to gauge himself against developmental benchmarks other than the purely quantitative aspect of learning. Without such benchmarks, it is difficult to see how awareness of continuous self-fuelled progress can be fostered. Surely this should be the underlying objective of all serious programmes for autonomous learning. Because such programmes are still fairly infrequent, it is difficult to see clearly what is happening here. Perhaps it is just a case of wishful thinking. This would explain why the percentage drops from $90 \%$ to $73 \%$ when the accent is switched from what is considered important to what really takes place.

Finally, a word on parameters that one would expect the sample to rate high but that are not. This is the case for Question 6 (mediation of goal-seeking, etc). Learners are frequently frustrated by not being in control of their own learning. Self-directed approaches underpin the notion of goal seeking and strive to neutralise the frustration by allowing the learners to take the reins. All teaching, autonomous or not, implies the fixing of objectives. Consequently, the pressing question arises as to what is really taking place when a concept that should theoretically rate high in fact rates fairly low in its perceived application (63\% - the lowest score for the entire questionnaire). Similar questions could be raised for Questions 7 and 9.

\section{A comparison with Chin's statistics}

Data on MLE applied to language learning is fairly sparse. The only other study of this kind was carried out by Chin when he was a student at Exeter University. The present comparison is based on what teachers consider important rather than what they actually do. The figures are average scores per question calculated from the responses of the entire sample. 9+ indicates that the question concerned scored a rounded-up average of 9 or more. 9- indicates that the question scored less than 9. There are some interesting similarities between Chin's sample and the present one. Teachers in both groups consider shared intentionality and reciprocity (Q1), competence (Q4) and control of behaviour (Q5) to be of primary importance. From an intuitive point of view it seems obvious that all teachers whatever their culture or the discipline they teach should feel concerned with concepts linked with working towards an objective, improving students' knowledge and language skills and maintaining order in the classroom.

Figure 2: Global Comparison with Chin's Results

\begin{tabular}{|l|l|l|l|l|l|l|l|l|l|l|l|l|}
\hline Question & 1 & 2 & 3 & 4 & 5 & 6 & 7 & 8 & 9 & 10 & 11 & 12 \\
\hline Chin & $9+$ & $9-$ & $9-$ & $9+$ & $9+$ & $9-$ & $9-$ & $9-$ & $9-$ & $9+$ & $9+$ & $9+$ \\
\hline
\end{tabular}




\begin{tabular}{|l|c|c|c|c|c|c|c|c|c|c|c|c|}
\hline Brown & $9+$ & $9-$ & $9-$ & $9+$ & $9+$ & $9-$ & $9-$ & $9-$ & $9-$ & $9-$ & $9-$ & $9-$ \\
\hline
\end{tabular}

41 The finer points of such concepts - what constitutes reciprocity, how competence is defined (fluency or accuracy) or what is symptomatic of lack of control - are doubtless culture-bound. On the other hand, whereas Chin's sample attributes importance to sharing (Q10), individuality (Q11) and belonging (Q12), the present one does not. Concepts of sharing and belonging are not the monopoly of any culture but they are readily associated with Eastern culture where the extended family, tribal structures and group organisation are still readily perceived as strong values. Do responses to questions 1,4 and 5 constitute the makings of a global teacher sub-culture? Nothing is less obvious. It is interesting to point out though, when the statistics are seen from this more general point of view, two of Feuerstein's essential parameters (meaning and transcendence) remain unfulfilled.

\section{Conclusion}

This study was driven by the realisation that not only is there room for improvement in our approach to teaching, but also that mainstream views on motivation in this age of learner-centredness tend to lay too much emphasis on the responsibilities of the learner. A resulting and all-too-frequent misinterpretation is that teachers may see this as a motive to disengage and to abandon not only their traditional approach, but also their traditional role. The desirability of such action may be brought into question.

MLE certainly does seem to be a going concern from the perceptual point of view. But as a set of teaching parameters it seems to be fuzzy with modes of application that are difficult to distinguish. This, of course, could be attributed to failings in the questionnaire. Furthermore, day-to-day language teaching can be disappointing or even tedious. Sometimes the counter-currents of unexpected setbacks and even curricular constraints make such approaches difficult to put into practice.

The idea of an international teaching sub-culture is intuitively appealing. Plainly similarities between professional groups will always exist. Are these sufficient to confirm the existence of such sub-cultures? An interesting comparison would have been to examine the attitudes of ethnic French teachers of English and mother-tongue teachers. Information concerning similarities or differences that occur closer to home are always easier to identify with. Further work is in progress along those lines.

\section{BIBLIOGRAPHIE}

Brown, David N. 2000. “Now you see me, now you don't: Another look at the role of the visual channel in video in language-teaching/learning". ASp 27-30, 379-385.

Chambers, Gary N. 1993. “Taking the 'de' out of demotivation”. Language Learning Journal 7, 13-16. 
Chambers, Gary N. 1996. “Listening. Why? How?”. Language Learning Journal 14, 23-27.

Chin, C. 1990. “An investigation into teachers' mediation with primary students learning English in Taiwan”. Unpublished MEd Dissertation, University of Exeter.

Covington, M. V. \& B. W. Roberts. 1994. "Self-worth and college achievement: Motivational and personality correlates". In Pintrich R., D. Brown and C. Weinstein (eds.), Student Motivation, Cognition, and Learning. New Jersey: Lawrence Erlbaum Associates, 157-187.

Feuerstein, R. \& Y. Rand. 1975. "Mediated learning experiences: an outline of the proximal etiology for differential development of cognitive functions". In Fein L. G., International Understanding: Cultural Differences in the Development of Cognitive Processes. New York: ICP, 7-37.

Feuerstein, R., Y. Rand, M. Hoffman \& R. Miller. 1980. Instrumental Enrichment: An Intervention Program for Cognitive Modifiability. Baltimore: University Press Park.

Gardner, R. C. \& P. D. MacIntyre. 1991. “An instrumental motivation in language study: Who says it isn't effective?". Studies in Second Language Acquisition 13, 57-72.

Paris, S. G. \& J. C. Turner. 1994. "Situated motivation”. In Pintrich R., D. Brown and C. Weinstein (eds.), Student Motivation, Cognition, and Learning. New Jersey: Lawrence Erlbaum Associates, 213-237.

Ryan, R. M. \& W. S. Grolnick. 1986. "Origins and pawns in the classroom: Self-report and projective assessments of individual differences in children's perceptions". Journal of Personality and Social Psychology 50, 550-558.

Warren, P. 1995. "An investigation into the use of tasks that develop both second lnguage learning and thinking skills with children". Unpublished MEd Dissertation, University of Exeter. Wlodkowski, R.J. 1993. Enhancing Adult Motivation to Learn. San Francisco: Jossey-Bass.

\section{ANNEXES}

\section{Appendix A: The MLE Questionnaire}


L'ENSEIGNANT FACE A SON GROUPE — QUESTIONNAIRE

Première partie : Veuillez entourer le chiffre qui correspond le mieux à votre avis.

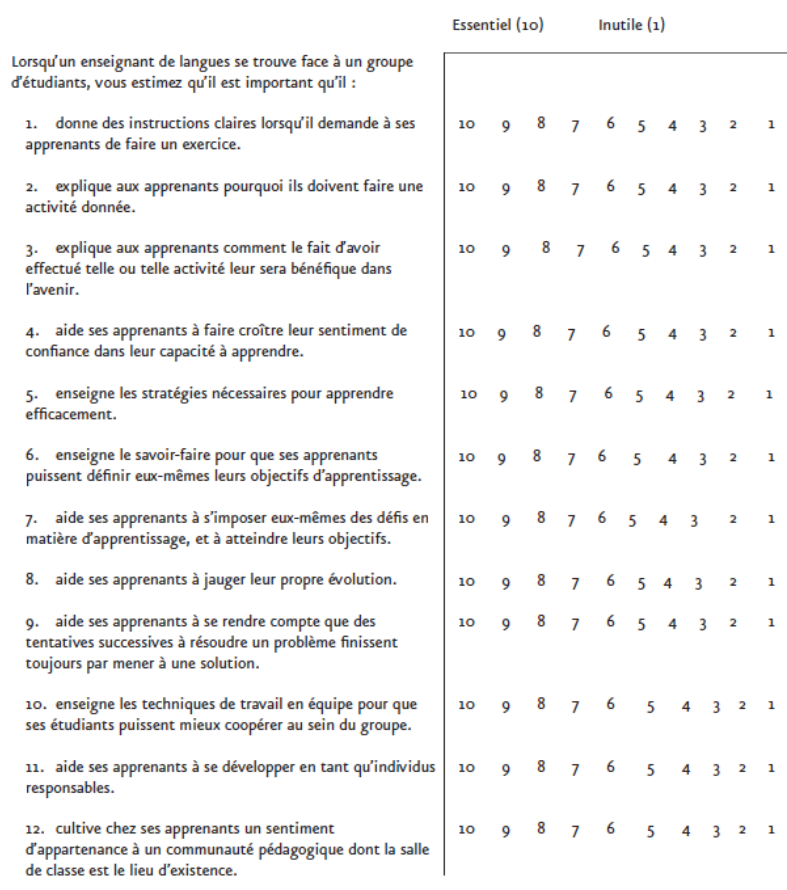

L'ENSEIGNANT FACE A SON GROUPE — QUESTIONNAIRE

Deuxième partie: Veuillez entourer le chiffre qui correspond le mieux à ce que vous faites réel-

lement.

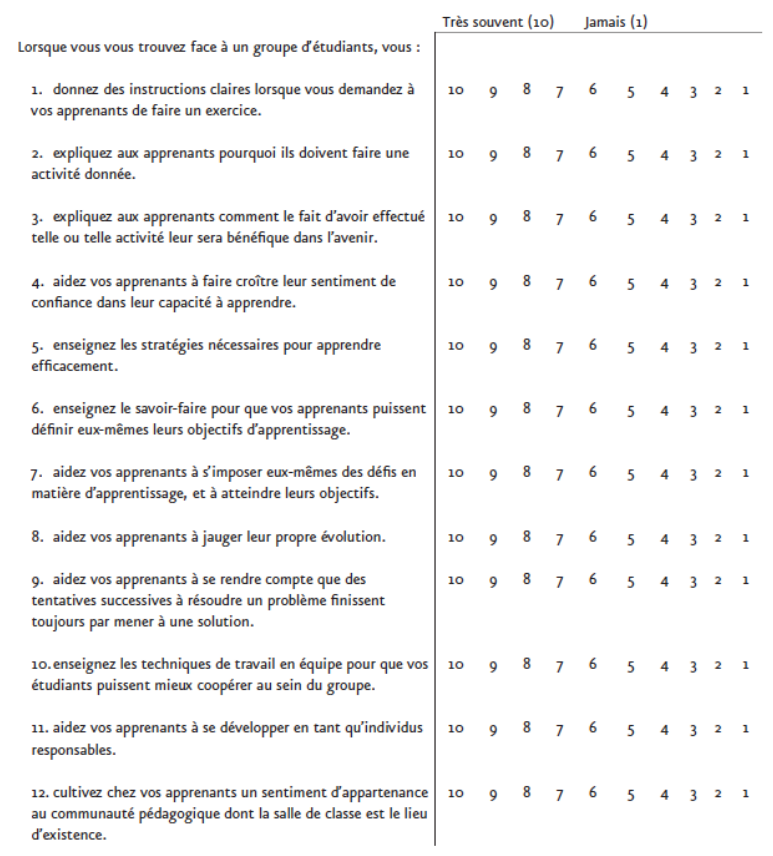

\section{Appendix B: Detailed Questionnaire Results}

Appendix B1: Scores attributed in Part I of the questionnaire 


\begin{tabular}{|l|l|l|l|l|l|l|l|l|l|l|l|l|}
\hline & Score & 10 & 9 & 8 & 7 & 6 & 5 & 4 & 3 & 2 & 1 & NR \\
\hline Question & & & & & & 5 & & & & & & \\
\hline 1 & & 69 & 14 & 1 & 3 & 3 & 0 & 0 & 0 & 0 & 0 & 0 \\
\hline 2 & & 48 & 12 & 5 & 4 & 6 & 9 & 0 & 6 & 0 & 0 & 0 \\
\hline 3 & & 37 & 14 & 6 & 6 & 9 & 3 & 3 & 4 & 2 & 0 & 6 \\
\hline 4 & & 51 & 20 & 7 & 9 & 3 & 0 & 0 & 0 & 0 & 0 & 0 \\
\hline 5 & & 46 & 11 & 8 & 16 & 6 & 0 & 3 & 0 & 0 & 0 & 0 \\
\hline 6 & & 33 & 18 & 2 & 7 & 6 & 12 & 3 & 0 & 5 & 4 & 0 \\
\hline 7 & & 20 & 19 & 21 & 10 & 2 & 12 & 6 & 0 & 0 & 0 & 0 \\
\hline 8 & & 34 & 17 & 15 & 15 & 0 & 5 & 1 & 3 & 0 & 0 & 0 \\
\hline 9 & & 40 & 5 & 16 & 6 & 6 & 6 & 0 & 0 & 1 & 11 & 0 \\
\hline 10 & & 39 & 12 & 9 & 15 & 3 & 9 & 3 & 0 & 0 & 0 & 0 \\
\hline 11 & & 40 & 20 & 7 & 8 & 0 & 9 & 0 & 0 & 1 & 2 & 3 \\
\hline 12 & & 40 & 8 & 12 & 12 & 3 & 6 & 3 & 3 & 0 & 0 & 3 \\
\hline
\end{tabular}

\section{Appendix B2: Scores attributed in Part II of the questionnaire}

\begin{tabular}{|l|l|l|l|l|l|l|l|l|l|l|l|l|}
\hline & Score & 10 & 9 & 8 & 7 & 6 & 5 & 4 & 3 & 2 & 1 & NR \\
\hline Question & & & & & & & & & & & & \\
\hline 1 & & 40 & 26 & 13 & 5 & 6 & 0 & 0 & 0 & 0 & 0 & 0 \\
\hline 2 & & 40 & 17 & 7 & 20 & 6 & 0 & 0 & 0 & 0 & 0 & 0 \\
\hline 3 & & 18 & 27 & 7 & 11 & 12 & 3 & 1 & 11 & 0 & 0 & 0 \\
\hline 4 & & 26 & 22 & 18 & 9 & 3 & 9 & 0 & 0 & 3 & 0 & 0 \\
\hline 5 & & 27 & 18 & 13 & 14 & 9 & 2 & 7 & 0 & 0 & 0 & 0 \\
\hline 6 & & 24 & 16 & 5 & 6 & 6 & 6 & 18 & 0 & 9 & 0 & 0 \\
\hline 7 & & 6 & 16 & 14 & 13 & 20 & 9 & 3 & 0 & 6 & 3 & 0 \\
\hline 8 & & 21 & 8 & 19 & 6 & 12 & 9 & 9 & 6 & 0 & 0 & 0 \\
\hline 9 & & 21 & 11 & 19 & 8 & 3 & 6 & 3 & 7 & 4 & 8 & 0 \\
\hline 10 & & 19 & 29 & 7 & 17 & 0 & 0 & 3 & 6 & 0 & 9 & 0 \\
\hline 11 & & 11 & 18 & 26 & 19 & 9 & 6 & 0 & 6 & 3 & 3 & 0 \\
\hline 12 & & 30 & 19 & 2 & 6 & 15 & 0 & 0 & 3 & 4 & 2 & 0 \\
\hline
\end{tabular}

\section{RÉSUMÉS}

Une rapide définition de l'apprentissage par médiation (AM) dans le contexte de l'apprentissage d'une langue étrangère est l'interaction de l'apprenant avec l'environnement d'apprentissage par l'intermédiaire de l'enseignant qui joue le rôle de médiateur. Dans la première partie de cet article, on examine en détail les douze paramètres définis par Feuerstein de l'AM tout en suggérant un schéma général d'application dans l'apprentissage des langues étrangères. La seconde partie analyse les réponses à un questionnaire en deux volets portant sur l'AM envoyé à presque 500 enseignants de langues. L'objectif du questionnaire était d'enquêter sur les attitudes et le comportement auto-perçu chez ces enseignants face à l'AM. Les résultats de l'enquête sont commentés et comparés à ceux obtenus par d'autres chercheurs travaillant dans le même domaine.

A brief definition of Mediated Learning Experience (MLE) within the context of foreign language learning is the interaction of a learner with the learning environment via the language instructor who assumes the role of human mediator. The first part of this paper explores Feuerstein's twelve parameters of MLE in detail and suggests a general template of how they can be applied to foreign-language learning. In the second part, a two-part MLE questionnaire sent out to almost 500 language teachers is analysed. The goal of this questionnaire was to investigate teacher attitudes and self-perceived behaviour in the light of MLE. The results drawn from the responses are discussed and compared with those obtained by other investigators working in the same field. 
INDEX

Keywords : culture, filter, learning, mediation, motivation, perception

Mots-clés : apprentissage, culture, filtre, médiation, motivation, perception

\section{AUTEUR}

\section{DAVID N. BROWN}

David N. Brown, ESSTIN, Université Henri Poincaré, Nancy. david.brown@esstin.uhp-nancy.fr 